\title{
Study Structure Formation of Microcrystalline Aluminum-Silicon Alloys Subjected to Compaction
}

\author{
Martin Lolov, Nikolay Dyulgerov, Stoyan Velev \\ Institute of Metal Science, Equipment and Technologies with Hydro- and Aerodynamics Centre "Acad. A. Balevski” Bulgarian Academy of \\ Sciences, Sofia, Bulgaria
}

Email address:

diulgerovi@abv.bg (N. Dyulgerov)

\section{To cite this article:}

Martin Lolov, Nikolay Dyulgerov, Stoyan Velev. Study Structure Formation of Microcrystalline Aluminum-Silicon Alloys Subjected to Compaction. American Journal of Mechanical and Materials Engineering. Vol. 2, No. 3, 2018, pp. 28-32. doi: 10.11648/j.ajmme.20180203.11

Received: July 16, 2018; Accepted: August 7, 2018; Published: October 12, 2018

\begin{abstract}
Microcrystalline structure of aluminum-silicon alloys is obtained by applaying high cooling rates (more than $10^{4} \mathrm{~K} . \mathrm{s}^{-1}$ ), which results in a highly non-equilibrum state in the form of suppersaturate solid solution. A product is obtained in the form of ribbons less than $100 \mu \mathrm{m}$ thick. These fine ribbons are usually subjected to consolidationby cold isostatic compaction followed by hot extrusion at relatively high temperatures (above $400^{\circ} \mathrm{C}$ ), in which phase transformations (decomposition of the supersatursted solid solution) and coarsening of the structure occur and this results in deterioration of the properties. The purpose of recent work is to study the structure formation at lower temperatures. These data will allow the development of technologies that save the finegrained two phase structureas much as possible after applied heat treatment action. The microstructures of the alloys are examined with a Reichert MeF2 optical microscope and the average area of the silicon particles $\left(\mathrm{S}, \mu \mathrm{m}^{2}\right)$ is determined as a measure of the structure dispersion. Particular stages in structural change are determined, both by X-ray analysis of crystal lattice parameters of the alluminium solid solution, and by the Perkin-Elmer DSC-2 Differential Scanning Calorimeter, with transient heating. X-ray tests are performed with a powder diffractometer DRON-3 ( $\mathrm{CuK}_{\alpha}$ filtered emission, scintillation registrtion, continuous recording on a chart band). The lattice parameter variation are used to examine the kinetics of structural changes in the microcrystalline state. Received curve shape suggests that the lattice parameter follows a parabolic dependence. A value of $94.6 \mathrm{~kJ} \cdot \mathrm{mol}^{-1}$ is obtained for activation energy of the decomposition of the solid solution at lower temperatures which was explained with acceleration of the Si diffusion process, due to the defects in the structure of the aluminum matrix. In the case of high temperature annealing at $400-500^{\circ} \mathrm{C}$ the activation energy of the process is $135 \mathrm{~kJ} \mathrm{~mol}^{-1}$ which was explained with the decomposition of the supersaturated solid solution. Coarsening process can be devided in two stages. During the first stage the particles reach size of several tens of nm. During the second stage, the average size of the silicon phase is in the micronial area. The temperature efect requires special measures for reduction of the microstructure coarsening. One of the possible ways is an additional alloying which is object of a further investigation.
\end{abstract}

Keywords: Rapid Crystalization, Microcrystalline Alloys, Aluminum-Silicon Alloys

\section{Introduction}

Microcrystalline alloys are of great interest because of their unique physical and technological properties due to the extremely small grain size. The synthesis of materials with microcrystalline structure can be achieved in two ways. The one way involves the application of significant plastic deformation at relatively low temperatures. The other way consists of microcrystalline structure obtaining by non- equilibrum crystallization. This allows a unique structural state of improved strength and plasticity to be achieved.

The rapid crystallization of microcrystalline alloys allows the creation of a new generation of high strength alloys with strength comparable to that of titanium. Whereas, the maximum strength of conventional aluminum alloys does not exceed 550 $\mathrm{MPa}$, titanium starts with a strength level from $750 \mathrm{MPa}$. Rapidly crystallized aluminum alloys allow filling the gap between aluminum and titanium. In addition to strengths, other properties such as thermal expansion, wear resistance and high- 
temperature strength can be significantly improved [1]. Among various rapidly solidified alloys hyper-eutectic AlSi alloys have attracted with growing interest due to their excellent properties, such as light-weight, good wear resistance, and low coefficient of thermal expansion (CTE) [12].

The recent achievments in the field of rapid solifidication of metal alloys is characterized by widening of the range of new alloys with structure and composition outside standard foundary and deformble alloys. Of particular importance is the possibility of processing of the aluminum scrap [2].

However, the preparation of a microcrystalline structure of aluminum alloys requires the application of high cooling rates of $\geq 10^{4} \mathrm{~K} \cdot \mathrm{s}^{-1}$, which results in alloys in a highly nonequilibrum state in the form of supersatureted solid solution of alloying and inpurity elements. This leads to a significant improvement in the homogeneity of the composition and structure of obtained microcrystalline alloy. It is characterized by reduced grain, colony, dendrite and individual phase sizes, which also determines the increased mechanical and anti-corrosion properties [3].

However, the product obtained in the rapid crystallization is usually in the form of ribbons less than $100 \mu \mathrm{m}$ thick. This necessitates further consolidation of the ribbons including heat treatment at elevated temperatures in view of the industrial application of the material. Typically, consolidation is achieved by hot pressing or hot extrusion at relatively high temperatures $\left(\geq 400^{\circ} \mathrm{C}\right.$ ) in which phase transformations (decomposition of the supersatursted solid solution) and coarsening of the structure occur and this results in deterioration of the properties. The microstructure and mainly the local clustering of Si phase during heat treatment play an important role in determining the mechanical properties because fracture initiates at the clusters and grows rapidly through the matrix [13]. Isothermal annealing of $\mathrm{Al}-12 \mathrm{wt} \% \mathrm{Si}$ alloy ribbons showed that the microstructure features of rapid solidification disappeared when the annealing temperature was above $250^{\circ} \mathrm{C}$ [14]. Their results indicated that the microstructure of rapidly solidified alloy was less stable. However, most of the rapidly solidified Al alloys are needed to be consolidated at the temperature above $250^{\circ} \mathrm{C}$ to obtain near full density [15]. Si particles grow predominantly via precipitation of the solute $\mathrm{Si}$ from the supersaturated solid solution below $300^{\circ} \mathrm{C}$ while coarsening is the predominant mechanism at higher temperatures [14]. It is also observed that with increasing annealing temperature second phase ( $\mathrm{Si}$ ) particles become more and more coarse. The microstructure reveals that silicon particles are spherical and randomly distributed in the aluminum matrix. This is attributed to outward diffusion of $\mathrm{Si}$ from a supersaturated solid solution of $\mathrm{Si}$ in Al. This causes nucleation of separate Si phase and as the annealing continues more and more Si comes out of the supersaturated solid solution. This continuous supply of Si during annealing causes growth and coarsening of Si nuclei into spherical Si particles. By increasing annealing temperature coursing of Si-particles take place [16].

The purpose of recent work is to study the structure formation at temperatures close to those required for compacting of microcrystalline ribbons. These data will allow the development of technologies that save the finegrained two phase structureas much as possible after applied heat treatment action.

\section{Materials and Methodology}

Microcrystalline ribbons of alloy with composition closed to AlSi11 are obtained in a one wheel facilityforplaner flow casting (PFC) used in our previous studies [4]. The contact surfaces of cooling wheel were made of copper. The strips have width of 7-12 $\mathrm{mm}$ and a thickness of 50-100 $\mu \mathrm{m}$.

Compacting of the metal strips was carried out in two stages:

1. Cold isostatic compaction at a specific pressure of $600-$ $650 \mathrm{MPa}$ to blanks with a diameter of $\varnothing 40 \mathrm{~mm}$ and a density of $70-75 \%$ of the theoretical one for these alloys.

2. Final compaction to massive blanks by hot extrusion. For this purpose a die with its own heater and the possibility for changing the degree of reduction is used. The extrusion was carried out at $723 \mathrm{~K}$ and a reduction degree of $1 / 12$.

The heat treatment of the ribbon samples was carried out in a laboratory electrical resistance furnace with low thermal inertia and high precision of addjustment. The rapid reach of the operating temperatures (up to $500^{\circ} \mathrm{C}$ for $60 \mathrm{~s}$ ) was facilitated by the small mass of the tested samples. They were packed in aluminum foil and were in good contact with the $\mathrm{NiCr}-\mathrm{Ni}$ thermocouple.

The microstructures of the strips after annealing as well as the compacted alloys were examined with a Reichert MeF2 optical microscope. The average area of the silicon particles $\left(\mathrm{S}, \mu \mathrm{m}^{2}\right)$ was determined as a measure of the structuredispersion.

Particular stages in structural change were determined, both by X-ray analysis of crystal lattice parameters of the alluminium solid solution, and by the Perkin-Elmer DSC-2 Differential Scanning Calorimeter, with transient heating. Xray tests were performed with a powder diffractometer DRON-3 $\left(\mathrm{CuK}_{\alpha}\right.$ filtered emission, scintillation registrtion, continuous recording on a chart band). The lattice cell parameters of the elemental cell of Al solid solution were determined by the angular position of the $\alpha_{1}$ component $(\lambda \mathrm{CuK} \alpha 1 \alpha 1=1.54056 \AA)$ of the line (422) recorded at an angular velocity of $1 / 8\left[{ }^{0} 2 \theta \mathrm{min}^{-1}\right]$. Polycrystalline silicon standard with lattice parameter $\mathrm{a}_{\mathrm{et}}=5.43088 \AA$ was used as an external standard. The analysis of the effects of microdeformations and the dimensions of coherent scattering blocks on the widths of the diffraction lines was performed by Hall's relation [11].

$$
\cos \theta(\Delta 2 \theta) / \lambda=1 /<\mathrm{L}>+\Delta \mathrm{a} / \mathrm{a} \cdot 2 \sin \theta / \lambda
$$

where: $\lambda$ is the wavelength, $\Delta 2 \theta$ is the semi-width of the diffraction line, $\theta$ is the Breg angle, $<\mathrm{L}>$ is the average size of the coherent scattering blocks, $\Delta \mathrm{a} / \mathrm{a}$ is the relative microdeformation.

The profiles of the diffraction lines (111), (200) and (220) 
recorded using $\mathrm{CuK} \beta$ radiation were investigated. The choice of radiation was made in order to avoid systematic errors in the determination of $\Delta 2 \theta$, which normally arise when using $\mathrm{CuK} \alpha 1, \alpha 2$ doublet radiation.

The degree of supersaturation of the aluminum matrix was determined by the concentration dependence of the lattice parameter $\mathrm{a}=\mathrm{f}\left(\mathrm{C}_{\mathrm{Si}}\right)$ of the Al-solid solution in the ribbons. Data from other authors was used for the calibration curve [5].

\section{Experimental Results and Discussion}

In our experiments (at cooling rates $>10^{4} \mathrm{Ks}^{-1}$ ), the aluminum matrix was supersaturted with silicon by between 2 and 4 weight percent. This was determined at room temperature by the reduction of the lattice parameter of the aluminium solid solution in comparison its equilibrium value [2]. In the process of heating above $120^{\circ} \mathrm{C}$ of binary $\mathrm{Al}-\mathrm{Si}$ microcrystalline alloys, the excess silicon leaves the solid solution, and the lattice parameter increases to a value of $4.0494 \AA$, which is very close to that of pure aluminum.

The lattice parameter variation can be used to examine the kinetics of structural changes in the microcrystalline state. Figure 1 shows experimental data obtained at four temperatures in the range $150-195^{\circ} \mathrm{C}$.

From the curve shape it can be suggested that the lattice parameter follows a parabolic dependence of the type $a^{n}=$ cons'.t. Figure 2 presents data in linearized coordinates $\mathrm{a}^{2} / \mathrm{t}$. The exponent $\mathrm{n}=2$ suggests a diffusion mechanism of the process. The good linear relation (Figure 2) makes it possible to study the variation of the lattice parameter during isothermal heating. From the temperature dependence of cons' in the parabolic dependence represented in the Areunius coordinates, it is possible to determine the activation energy of the decomposition process of the supersaturated solid solution.

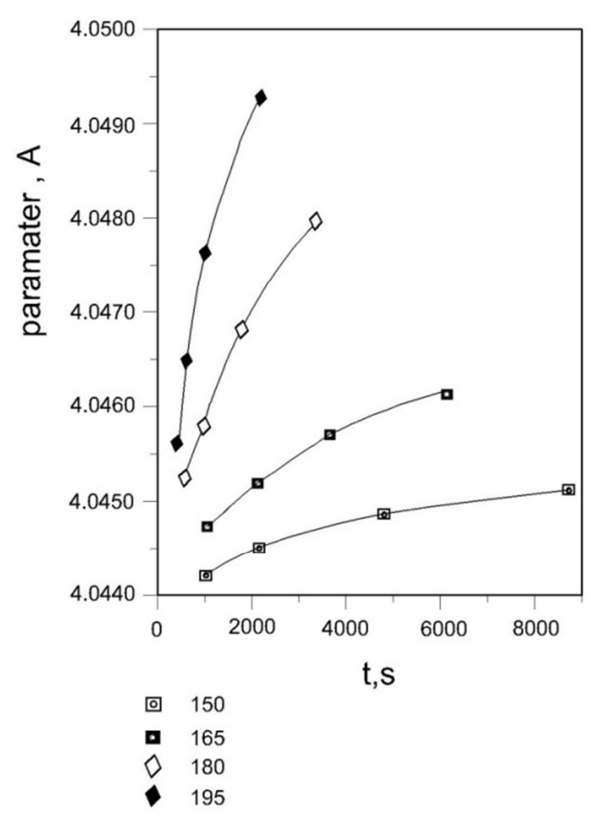

Figure 1. Aluminum matrix lattice parameter increase in microcrystalline AlSil1 alloy at isothermal annealing temperatures of 150, 165, 180 and $195^{\circ} \mathrm{C}$.
A value of $94.6 \mathrm{~kJ} . \mathrm{mol}^{-1}$ is obtained for activation energy. I.e. the decomposition of the solid solution proceeds at a significantly lower activation energy than the $135 \mathrm{~kJ} \cdot \mathrm{mol}^{-1}$ obtained by other authors for Si-diffusion in massive alloys [9]. This value is comparable to that determined in [7] for temperature-activated processes in microcrystalline alloys, as well as that defined in [6] for the case of sprayed thin films. We accept the explanation made in [6] and [7] that the acceleration of the Si diffusion process is due to the defects in the structure of the aluminum matrix received during material preparation.

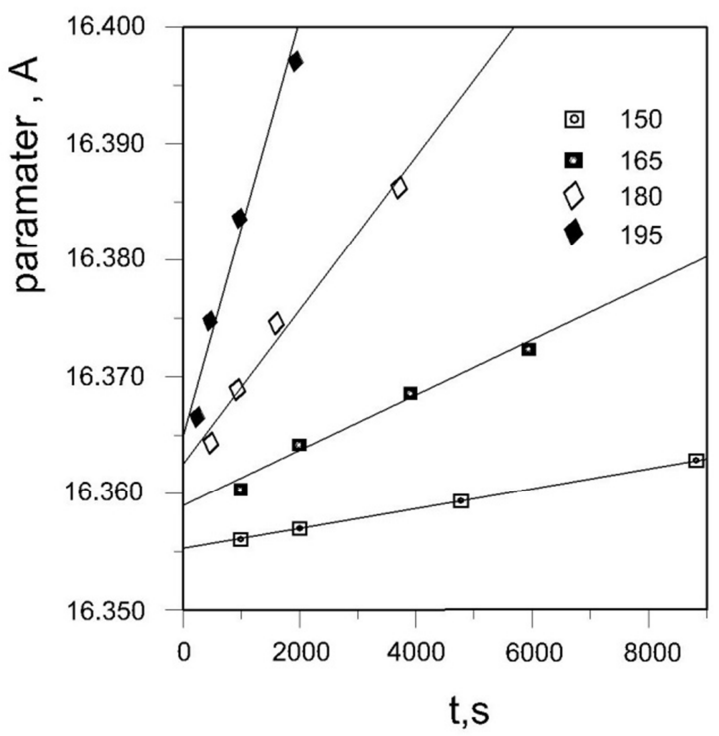

Figure 2. Increase of the lattice parameter of the aluminium matrix at 150, 165,180 and $195^{\circ} \mathrm{C}$.

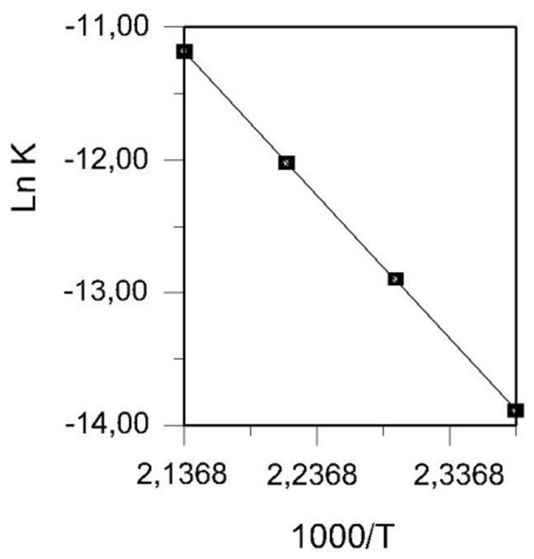

Figure 3. Temperature dependence of the constants of Figure 2 in Arentus coordinates.

The dependence of the widths of the diffraction lines on the wave length is shown in Figure 4. The widening of the Xray diffraction lines of the initial ribbon(as-cast) is due to the presence of the microdeformations $(\Delta \mathrm{a} / \mathrm{a} \approx 0.2 \%)$ as well as to the final dimension of the coherent scattering blocks ( $\sim \sim 520 \AA)$ which approximates the size of the dendrites of aluminum solid solution in the initial microcrystalline alloy. The heating of the microcrystalline ribbon at $450^{\circ} \mathrm{C}$ is 
accompanied by annihilation of the defects of the packing and the increase of the dimensions of the coherent dispersion blocks. Low temperature annealing allows realization of the silicon segregation from supersaturated initial matix at a submicron level. Furthermore, the coherent X-ray scattering blocks effectively reduce and the temperatures for matrix recrystallization and the respective $\mathrm{Si}$ particles growth are low.

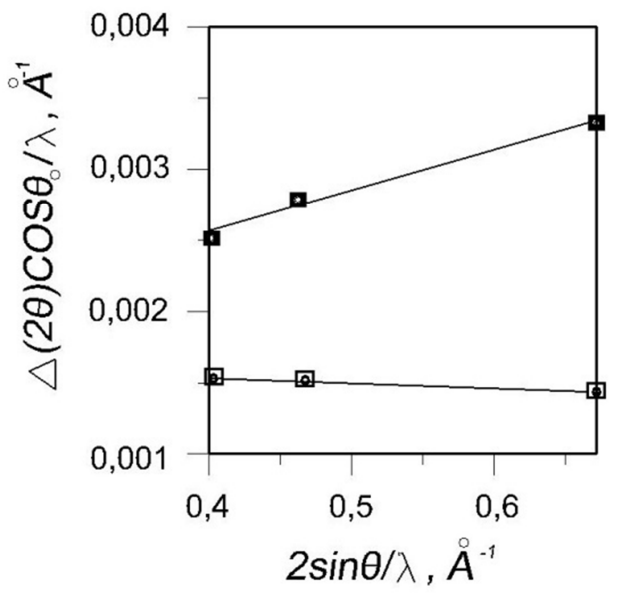

Figure 4. Dependence of the widths of the diffraction lines on the X-ray wavelength in the test ribbons in the initial (a) and the heat treated (b) at $450^{\circ} \mathrm{C}$ condition.

According to [8], in the case of high temperature annealing at $400-500^{\circ} \mathrm{C}$, a coarsening of the structure is observed. The activation energy of the process is $135 \mathrm{~kJ} . \mathrm{mol}^{-1}$, a value reported also by other authors [9]. It can be assumed that, at high temperatures, the defects significantly reduce and the diffusion delay, as the activation energy reaches the stated higher value. Two major stages in forming the structure are distinguished: 1-decomposition of the supersaturated solid solution and 2-coarsening of the structure. These stages are characterized by different values of activation energy (Figure 5) and contribute to formation of the final structure of massive specimens.

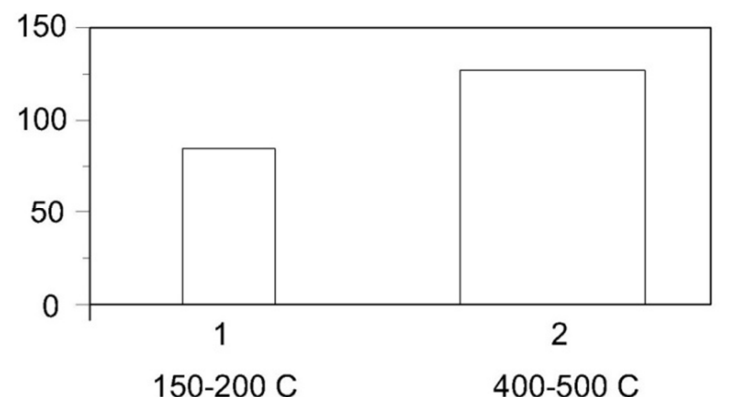

Figure 5. Dependence of the activation energy from the annealing temperature.

During the first stage the structure changes substantially. Initial structure is a typical hypoeutectic. Si particals have a size of several nanometers and they a located at dendrite boundaries of the aluminum phase which has an avarage size of $500 \mathrm{~nm}$. At the end of the first stage a Si phase is already segregated with a size of dozens nanometers - Figure $6 a, b$, c. At these temperatures, the main thermal effect of the decomposition process of the supersaturated solid solution is also observed - DSC analysis data [10].

During the second stage an increase of the secondary phase particles is noted - Figure 6d.

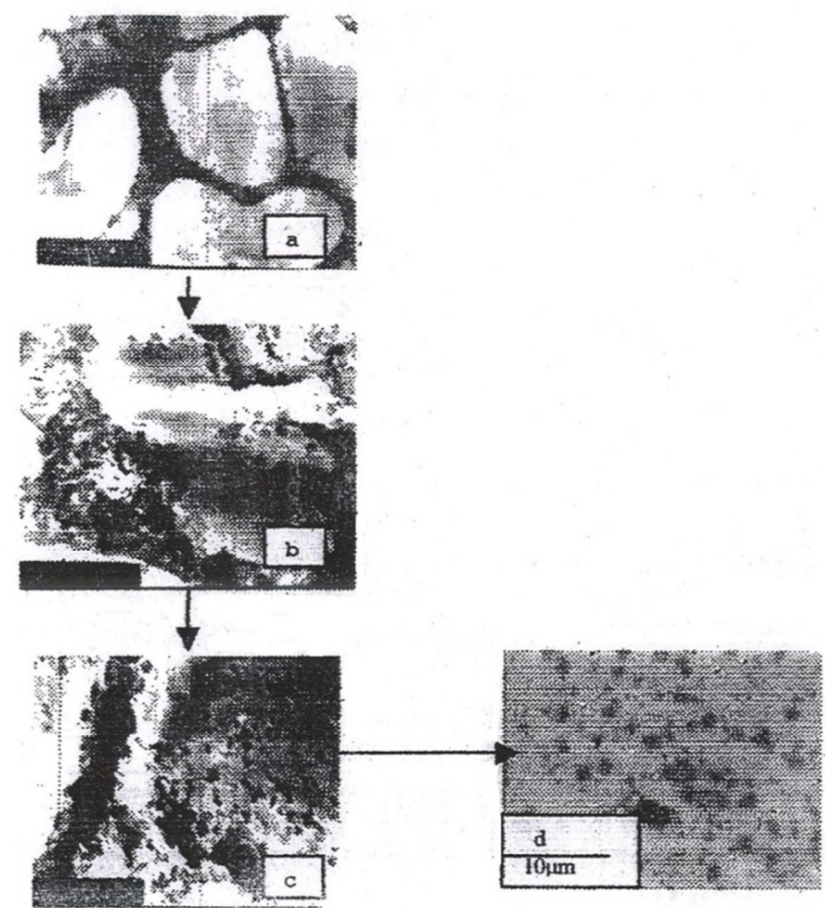

Figure 6. Microstructure after different anealingtemeratures.

Obvously properties of consolidated rapid crystallized ribbons of AlSi alloys have to be further improved by microstructural alteration processes, termed as modification processes. These modification techniques can be classified into three:

i. Chemical modification processes: addition of a calculated amount of nucleation agents

ii. Mechanical modification processes: ultrasonic, squeeze, stirring, centrifugal, and vibration methods

iii. Thermal modification process: superheating, quench and cooling

Chemical modification, which is the addition of trace levels of certain elements, into aluminium alloys, is most effective [17].

\section{Conclusions}

The rapid solidified microcrystalline AlSi alloys have a typical hypoeutectic structure with $\mathrm{Si}$ particles segregated on dendrite boundary. The size of the particals is in the range of 5-6 nm. This structure guarantees mechanical characteristics suitable for further plastic deformation treatment. In the compaction process, the ribbons undergo a thermal action, resulting in a substantial increase in Si particles size. The process of coarsening of the structure can be divided into two 
stages: during the first particles reach size of several tens of $\mathrm{nm}$. During the second stage, the average size of the silicon phase isin the micronial area. The temperature efect requires special measures for reduction of the microstructure coarsening. One of the possible ways is an additional alloying which is object of a further investigation.

\section{References}

[1] L. Katgerman, Rapidely solidified aluminium alloys by meltspinning, Material Science and Engineering:A, vol. 375377 , July 2004, pp 1212-1216

[2] E. J. Lavernia, J. D. Ayers, T. S. Srivatsen Int. Materials Reviews, 37, No 1, pp. 1-45, 1992

[3] V. S. Muratov, Peculiarities of structure formation and properties of rapidly solidifies aluminum alloys, Metal science and heat treatment of metals, No 5, p.31, 1997 (in russian)

[4] S. Yaneva, I. Peychev, N. Stoychev, D. Zidarov, G. Zlatev, N. Dyulgerov, AMTECH'93, Scientific conference "Progressive machinebuilding technologies, 17-19 May, 1993, Russe, Coleection of reports, Section 3 "Heat treatment and coatings, pp 209-215, 1993 (in bulgarian)

[5] M. van Royen, H. van der Pers, Th. De Keijser, E. J. Mitemeier, Mat. Sci. Eng. 96, p.17-25, 1987

[6] J. O. McCaldin, H. Sankur, Diffusivity and Solubility of Si in Al Metallization of Integrated Circuits, Appl. Phycs Letters, 19, No 12, pp. 524-527, 1971

[7] P. van Mourik, E. J. Mittemeijer, Th. H. de Keijser, On the Precipitation in rapidly solidified aluminium-silicon alloys, J. Mat. Sci.18, pp. 2706-2720, 1983
[8] N. Stoichev, S. Yaneva, P. Covachev, E. Momchilova, E. Vladkova, Influence of Strontium of Microcrystalline Structures in Al-Si Alloys, Int. J. of Rapid Solid., 9, pp. 33-44, 1995

[9] Shin-IchiroFujikawa, Ken-Ichi Hirano, Yoshiaki Fukushima, Diffusion of Silicon in Aluminium, Met. Trans. A, 9A, pp. 1811-1814, 1978

[10] S. Yaneva, N. Stojchev, P. Kovachev, N. Dyulgerov, I. Peichev, proc. Of the $8^{\text {th }}$ Intena-tionalMetallutgy and Materials Congress, 6-9 June, Istanbul, p. 1055, 1995

[11] W. H. Hall, proc. Phys. Soc., 62A, pp. 741, 1949

[12] Z. Cai, R. Wang, C. Zhang, C. Peng, L. Wang, Journal of Materials Science: Materials in Electronics. Volume, 26, pp 4234-4240, 2015

[13] J. V. Goñi, J. M. Rodriguez-Ibabe, J. J. Urcola, Scr. Mater. 34 483-489, 1996

[14] Y. Birol, J. Alloy. Compd. 439, pp81-86, 2007

[15] ZhiyongCai, Chung Zhang, Richu Wang, ChaoqunPeng, KeQiu, Naiguang Wang, Progress in Natural Science\& Materials International, 26 pp. 391-397, 2016

[16] Maftah H. Alkathafi and Awanikumar P. Pati, International Journal of Scientific \& Engineering Research, Volume 4, Issue 11, November 2013

[17] Williams S. Ebhota and Tien-Chien Jen, Effect of Modification Technicques on Mechanical properties of Al-Si Cast Alloys, Chapter 4 of the book AluminiumAlloysRecent Trends in Processing, Characterization, Mechanical behavior and Applications, Edited by Subbarayan Sivasankaren, IntechOpen, 2017 